\title{
O DIREITO FUNDAMENTAL À PRESUNÇÃO DE INOCÊNCIA, A TEORIA DA INTEGRIDADE DE RONALD DWORKIN E O JULGAMENTO DO HC 152.752 (CASO LULA)
}

\author{
Rafael Da Nóbrega Alves Praxedes* \\ Juraci Mourão Lopes Filho*
}

Resumo: O estudo aborda a execução da pena de prisão antes do trânsito em julgado, examinando o HC 152.752, sob a teoria da integridade de Ronald Dworkin que busca abolir a ideia de um poder discricionário forte dos julgadores, por meio da única resposta correta possível. Alguns votos proferidos, entretanto, demonstram um verdadeiro decisionismo. A presunção de inocência faz parte do senso de justiça do brasileiro, equivocando-se o STF nesse caso. Foram utilizadas fontes documentais e bibliográficas. Conclui-se que, de acordo com a teoria de Dworkin, a resposta correta seria a proibição da execução da pena antes do trânsito em julgado.

Palavras-chave: Presunção de Inocência. Direito Fundamental. Ronald Dworkin. Teoria da Integridade. Discricionariedade.

\section{THE FUNDAMENTAL RIGHT TO THE PRESUMPTION OF INNOCENCE, RONALD DWORKIN'S THEORY OF INTEGRITY AND THE JUDGMENT OF HC 152.752 (CASE LULA)}

\begin{abstract}
The study addresses the execution of the pre-sentencing prison sentence, examining HC 152.752, under Ronald Dworkin's theory of integrity that seeks to abolish the idea of a strong discretionary power of the judges, through the only possible correct answer. Some votes cast, however, demonstrate an excessive decisionism. The presumption of innocence is part of the sense of justice of the Brazilian, mistaking the STF in this case. Documentary and bibliographic sources were used. It is concluded that, according to Dworkin's theory, the only correct answer would be the prohibition of execution of the sentence before finality.
\end{abstract}

Keywords: Presumption of Innocence. Fundamental Right. Ronald Dworkin. Theory of Integrity. Discretion.

\section{INTRODUÇÃO}

Por ocasião do julgamento do Habeas Corpus 152.752, no qual figurava como paciente o ex-Presidente da República, Luiz Inácio Lula da Silva, foi reacendida a discussão

\footnotetext{
"Mestrando em Direito e Desenvolvimento (UNICHRISTUS), pós-graduado lato senso em Direito e Processo do Trabalho. Advogado. rafaelpraxedesadv@ gmail.com

"Doutor em Direito Constitucional (UNIFOR), Mestre em Direito (UFC), pós-graduado lato senso em Direito Processual Civil (UFC). Professor do programa de pós-graduação stricto sensu do Centro Universitário Christus - UNICHRISTUS. Procurador do Município de Fortaleza. Advogado. juracimourao@ gmail.com
} 
acerca da possibilidade, ou não, do início da execução da pena de prisão de um réu condenado apenas em segunda instância sem que a sentença penal condenatória tenha transitado em julgado.

Após horas de julgamento, em um placar apertado de 6 votos a 5 - já indicativo dos desacordos verificados nas posições de cada ministro -, o plenário do Supremo Tribunal Federal denegou o Habeas Corpus impetrado. Assim, foi mantido o entendimento de autorizar o início da execução da pena de réus condenados em segunda instância sem o esgotamento dos meios recursais.

Entre os votos vencedores, chamaram atenção as interpretações diversas dos ministros acerca do disposto no artigo 5 ${ }^{\circ}$, LVII da Constituição Federal e do artigo 283 do Código de Processo Penal, além das fundamentações das decisões. De maneira que ficou claro o poder discricionário dos julgadores que decidiram com base em convicções morais próprias - com a utilização de estatísticas, argumentos retóricos ou invocação de um "princípio da colegialidade" - revelando mesmo concepções de Direito não integradas com a moralidade política identificada nas várias outras decisões da comunidade de princípios.

O presente artigo busca, então, realizar a análise de algumas fundamentações dos votos vencedores do caso em comento a partir da discussão acerca do princípio de presunção de inocência como garantia fundamental. Tomando como ponto de vista o Direito como integridade, em que, segundo Ronald Dworkin, as decisões dos julgadores devem ser embasadas na busca de uma resposta correta com base na comunidade de princípios.

O próprio placar apertado da votação no julgamento do HC 152.752 já é indicativo da grave controvérsia acerca do tema que precisa ser discutido além do âmbito dos tribunais, merecendo atenção também da academia.

É necessária uma reflexão acerca da interpretação e consequentemente da discricionariedade dos julgadores na aplicação do direito, especialmente no que tange aos ministros do Supremo Tribunal Federal. Estes decidem, quase diariamente, inúmeros casos de interesse nacional, fundamentando suas decisões muitas vezes "conforme com sua[s] consciência[s]", sendo cada vez mais comum encontrar os mais diversos entendimentos de acordo com as posições individuais de cada um.

Essa constatação é verdadeira para o Supremo Tribunal Federal, mas o panorama atual do Judiciário brasileiro (em tempos de "neoconstitucionalismo") tem destinado aos 
julgadores a possibilidade de decidir casos idênticos de maneiras completamente diferentes. Conceitos abertos previstos na legislação e na Constituição Federal são utilizados como veículos para inserção de juízos morais individuais projetados como se fossem juízos da sociedade em geral.

Neste trabalho, com as limitações materiais que lhe são inerentes, pretende-se demonstrar que a presunção de inocência, enquanto uma garantia fundamental, traduz escolhas de moral política da sociedade observadas em princípios que perpassam ao longo da formação da realidade institucional brasileira ${ }^{1}$. Nessa perspectiva, a execução provisória da pena contraria essa longa linha principiológica. Pode até traduzir algum tipo de anseio popular difuso e ainda indefinido, mas não pode ainda ser traduzido como uma mudança da própria moralidade política que conforma a comunidade de princípios em que está inserido o texto constitucional interpretado.

Utilizou-se o método hipotético-indutivo com a análise crítica de documentos oficiais, especialmente, em relação à fundamentação de alguns votos vencedores no HC 152.752, além do embasamento da pesquisa em acervo bibliográfico e periódicos científicos.

$\mathrm{O}$ estudo foi desenvolvido em três tópicos: abordando-se primeiramente o princípio da presunção de inocência e seu caráter de garantia fundamental prevista pela Constituição Federal moldado por longa linha de decisões institucionais que traçam a moralidade política que lhe é subjacente e que não pode ser substituída por moralismos ocasionais dos julgadores. Busca-se, assim, uma conceituação e contextualização acerca dos direitos fundamentais na atualidade. Além disso, cita-se o artigo 283 do CPP como efetivação do princípio constitucional em uma lei hierarquicamente inferior.

Em seguida, tenta-se entender a teoria do Direito como integridade de Ronald Dworkin, diferenciando uma teoria descritiva de uma teoria interpretativa para criticar o positivismo no que tange à interpretação e ao excessivo poder discricionário dos julgadores. Para que exista integridade no Direito, casos concretos devem ser interpretados à luz da comunidade de princípios, buscando uma resposta correta.

No terceiro e último momento, será feita uma breve análise do julgamento do STF no HC 152.752. Pretende-se analisar, a título ilustrativo, as fundamentações das decisões do Ministro Luís Roberto Barroso e da Ministra Rosa Weber - que inclusive cita

\footnotetext{
${ }^{1}$ Várias outras decisões, não apenas judiciais, mas também de outras instituições e mesmo de agentes privados.
} 
(equivocadamente) Ronald Dworkin - sem qualquer intenção de esgotamento da análise dos votos até em virtude da extensão dos mesmos, buscando um paralelo com a teoria da integridade, com o juiz Hércules e com a comunidade de princípios em relação á garantia fundamental da presunção de inocência e a (im)possibilidade de execução da pena restritiva de liberdade após a condenação em segunda instância.

\section{A PRESUNÇÃO DE INOCÊNCIA COMO DIREITO FUNDAMENTAL E COMO PRINCÍPIO DE JUSTIÇA}

Em tempos de vulgarização dos direitos fundamentais faz-se necessário entender suas particularidades para não confundir com outros termos, tais como direitos humanos. Direitos fundamentais se distinguem dos demais tendo em vista a sua aplicação imediata, sua hierarquia, por estarem positivados na Constituição e pelo fato de que são cláusulas pétreas, não podendo ser suprimidos do ordenamento jurídico. São, portanto, normas fundadas na dignidade da pessoa humana e na limitação do poder estatal que, positivadas constitucionalmente, validam, em última análise, o próprio Estado Democrático de Direito (MARMELSTEIN, 2014).

A verdadeira expressão do objetivo de colocar o ser humano no centro do ordenamento jurídico, como sujeito de direitos, protegendo a honra, a moral, a integridade física, a liberdade, entre outros, são os direitos fundamentais.

Quando determinados direitos humanos são positivados no ordenamento jurídico, passam a ser direitos fundamentais, desde que o dito ordenamento lhes conceda um status especial em relação aos demais direitos ${ }^{2}$ (ROBLES, 1992).

Direitos fundamentais como normas constitucionalmente positivadas referem-se aos princípios adotados a partir da escolha da ideologia política de cada Estado. No caso brasileiro, optou-se pelo Estado Democrático de Direito para a proteção das garantias individuais e coletivas a partir do conceito de soberania popular (SILVA, 2014).

\footnotetext{
${ }^{2}$ No texto original: "Una vez que los derechos humanos, o mejor dicho, determinados derechos humanos, se positivizan, adquiriendo categoria de verdaderos derechos protegidos procesalmente, pasan a ser derechos fundamentales em um determinado ordenamento jurídico. Ahora bien, esto solamente sucede cuando dicho ordenamento les dota de un status especial que les hace distintos, más importantes, que los demás derechos. Si no fuera así no habria modo de distinguir los derechos fundamentables de aquellos otros que son, por decirlo así, derechos corrientes".
} 
A positivação de direitos fundamentais é uma das principais características das constituições atuais, incluindo a Constituição Federal de 1988, que, promulgada após um longo período de ditadura militar, preocupou-se claramente com a efetivação desses direitos, colocando a dignidade humana como valor central da sociedade (PEREIRA, 2006).

Conforme demonstram estudos de Luigi Ferrajoli,

\begin{abstract}
Acrescento que os direitos fundamentais estabelecidos nas constituições, se por um lado servem para limitar a democracia política, por outro servem para integrá-la e, por assim dizer, para reforçá-la juntamente com a noção, que está sobre seus ombros, de "soberania popular". Todos os direitos fundamentais, de fato - não só os direitos políticos, mas também os direitos civis, os direitos de liberdade e os direitos sociais -, sendo conferidos igualmente a todos enquanto pessoas ou cidadãos, aludem a todo o "povo", referindo-se a poderes e a expectativas de todos, ainda mais do próprio princípio de maioria. A sua constitucionalização, elevando-os como normas supraordenadas a qualquer outra, confere aos seus titulares - ou seja, a todos os cidadãos de carne e osso - uma posição, por sua vez, supraordenada ao conjunto dos poderes públicos que a seu respeito e a sua garantia são vinculados e funcionalizados (FERRAJOLI, 2011, p. 518).
\end{abstract}

A magna carta brasileira, dessa maneira, inspirada pelo nascimento das constituições de cunho social típicas da segunda metade do século XX, elevou a importância dos direitos fundamentais, elencando diversas garantias individuais e coletivas.

No título dos direitos e garantias fundamentais, capítulo dos direitos e deveres individuais e coletivos, prescreve no artigo $5^{\circ}$, LVII que "ninguém será considerado culpado até o trânsito em julgado de sentença penal condenatória”. Não há como negar que a prescrição obtida desse enunciado constitucional é o princípio da presunção de inocência, que deve ser tomado como sendo mais do que uma simples presunção de não-culpabilidade, haja vista sua origem liberal e democrática que vem desde a Declaração dos Direitos do Homem e do Cidadão, influenciada por ideais iluministas (GOMES, 1996).

Percebe-se, por meio de uma simples leitura do dispositivo citado, que o princípio da presunção de inocência foi adotado de forma consciente pelo legislador constituinte como verdadeira garantia fundamental. Não é possível se suscitar maiores dúvidas hermenêuticas diante do incontroverso enunciado constitucional.

Na mesma trilha principiológica, o legislador infraconstitucional não só assumiu a presunção de inocência adotado pela Constituição como, ao elaborar o Código de Processo 
Penal, estabeleceu o artigo 283, mencionando de forma clara a impossibilidade de prisão antes do trânsito em julgado da sentença penal condenatória ${ }^{3}$.

Uma garantia constitucional é, em última análise, um dos atributos da dignidade humana que por sua vez é fundamento da república. Nas palavras de André Luiz Nicolitt:

\begin{abstract}
A toda evidência, percebemos que a dignidade humana é importante na orientação do processo penal, já que é a raiz das garantias constitucionais que devem inspirar a atividade jurisdicional do Estado, notadamente no que tange às dimensões expostas relativas à individualidade, à liberdade, à autonomia frente ao poder público e à igualdade de tratamento normativo (NICOLITT, 2017, p. 163).
\end{abstract}

A presunção de inocência é, portanto, muito mais do que um direito subjetivo, pois trata-se de verdadeira garantia constitucional que deve ser aplicada sem discriminação a todos os indivíduos, orientando, ainda, a atividade objetiva do Estado e as posturas interpretativas em face dos enunciados normativos, de modo que a supressão desse princípio de forma casuística poderá representar um alto risco para a sociedade (OLIVEIRA NETO, 2018).

A positivação da garantia fundamental à presunção de inocência é fruto do resultado da moralidade política existente na comunidade de princípios formada pelos cidadãos brasileiros. Há, entre os membros da sociedade, a partilha de valores os quais são essenciais para o desenvolvimento da vida em comunidade, os quais são espalhados em várias decisões políticas da comunidade por suas várias instituições.

Não restam dúvidas de que para a sociedade atual, a presunção de inocência é um valor basilar que traduz o senso de justiça, pois não há como imaginar uma privação da liberdade sem a existência de um processo penal devidamente instruído e sem a possibilidade de recursos. Daí sua natureza de garantia, pois é instrumento hábil na salvaguarda de um direito fundamental strictu sensu, no caso, a liberdade. A presunção de inocência representa, nesse contexto, um princípio de justiça compartilhado pela sociedade brasileira.

\title{
3 A TEORIA DA INTEGRIDADE DE RONALD DWORKIN: UMA TENTATIVA DE ABOLIR A DISCRICIONARIEDADE FORTE
}

\footnotetext{
${ }^{3}$ Art. 283. Ninguém poderá ser preso senão em flagrante delito ou por ordem escrita e fundamentada da autoridade judiciária competente, em decorrência de sentença condenatória transitada em julgado ou, no curso da investigação ou do processo, em virtude de prisão temporária ou prisão preventiva (CÓDIGO PROCESSO PENAL, 2017).
}

Revista de Teorias do Direito e Realismo Jurídico | e-ISSN: 2525-9601 | Porto Alegre | v. 4 | n. 2 | p. $72-89$ | Jul/Dez. 2018 
De modo distinto dos teóricos positivistas que buscam dizer o Direito a partir de uma análise descritiva, Ronald Dworkin tomou para si a difícil tarefa de construir uma teoria interpretativa.

Uma de suas principais críticas ao positivismo que ficou clara no célebre debate Hart-Dworkin $^{4}$ diz respeito à possibilidade de o juiz, nos casos de lacunas de legislação, criar o direito no caso concreto. A desaprovação seria, desse modo, em relação à livre discricionariedade que o julgador teria para decidir um conflito.

Para Kelsen (1999), por exemplo, cujas lições não estão integralmente inseridas nas premissas desse debate, o Direito a ser aplicado pelo intérprete produziria uma "moldura", possibilitando que várias decisões diferentes acerca de um mesmo caso estivessem de acordo com o Direito vigente, desde que inseridas dentro da referida moldura. $\mathrm{O}$ agente interpretador teria, portanto, o poder discricionário para decidir no caso concreto.

Hart (2009), no entanto, traz uma perspectiva um pouco distinta. Para ele, a legislação, como parte integrante da própria linguagem utilizada como forma de comunicação classificatória de questões fáticas, possuiria uma zona de foco de certeza positiva (que indicaria sentidos claramente atribuíveis ao enunciado normativo) e uma zona de foco de certeza negativa (com intepretações evidentemente impossíveis de serem atribuídas ao texto). Contudo, ao lado dessas certezas, haveria uma “zona de penumbra”, na qual não seria possível determinar com segurança se um determinado sentido pode ou não ser inferido de um texto normativo. Além disso, haveria uma "textura aberta", que permitiria a mudança das zonas de foco e de penumbra. Diante da zona de penumbra e mesmo em face da textura aberta, haveria casos em que os tribunais estariam aptos a realizarem escolhas discricionárias de interpretações e, consequentemente, de decisões ${ }^{5}$.

\footnotetext{
${ }^{4}$ Shapiro (2007), no artigo intitulado "The Hart-Dworkin Debate: A Short Guide for the Perplexed", aborda de maneira didática e imparcial o famoso debate entre Ronald Dworkin e Hebert Hart, analisando, do pon to de vista contemporâneo, os argumentos dos teóricos, passadas quatro décadas desde a publicação do "Modelos de regras I" por Dworkin, o qual trazia as primeiras críticas mais contundentes aos estudos realizados por Hart.

${ }^{5}$ Nessa direção, em relação às inúmeras possibilidades geradas pela utilização da linguagem: "Mesmo nos casos em que se fala que o texto legal é "claro", não havendo lugar para o papel criador do intérprete, não se deve esquecer que o caso concreto - ao qual a norma será aplicada, e que influenciará na determinação do seu sentido - pode apresentar nuances que tornam o texto, ou o seu sentido, bem menos claro. $\mathrm{O}$ enunciado normativo que simplesmente afirma "é proibida a entrada de cães" pode ser muito claro, mas essa clareza se dissipa quando chega ao lugar um cego com um cão guia, animal adestrado que a ninguém incomoda e sem o qual o cego não pode locomover-se com a mesma desenvoltura" (MACHADO SEGUNDO, 2008, p. 36).
} 
A teoria fornecida pelo positivismo para que casos difíceis sejam decididos quando não há regras claras a serem aplicadas, apesar de fazer parecer que uma das partes possuía um direito anterior a ganhar a causa, seria na verdade uma criação do direito por parte do julgador, por meio de seu poder discricionário, aplicado de maneira retroativa ao caso em comento (DWORKIN, 2010).

O positivismo ${ }^{6}$, concentrado na sua tarefa de descrever o Direito, concedeu menos importância à interpretação, pois uma teoria hermenêutica jamais poderia ser inteiramente descritiva e geral, mas sempre normativa e especial. Gerou-se, então, um problema epistemológico, que se tentou remediar com a concessão do poder discricionário aos julgadores, conforme apontado por Lenio Streck sobre a posição do positivismo em relação à interpretação e à discricionariedade do julgador:

Resgatar o mundo prático do direito e no direito significa colocar a interpretação no centro da problemática da aplicação jurídica, explorar o "elemento hermenêutico" da experiência jurídica e enfrentar aquilo que o positivismo desconsiderou: o espaço da discricionariedade do juiz e o que isso representa na confrontação com o direito produzido democraticamente (STRECK, 2011, p. 46).

Desse ponto de vista, a teoria positivista não conseguiu desenvolver suficientemente o estudo da interpretação sem desvencilhar-se da ideia de poder discricionário do aplicador das leis.

$\mathrm{Na}$ tentativa de combater o problema da discricionariedade do julgador, ao longo de sua obra, Dworkin construiu uma visão interpretativista, que parte da premissa de que não é possível descrever objetivamente o Direito e que os desacordos verificados nas várias descrições não são compreendidas como uma falha em retratar a realidade descrita, mas como desacordos teóricos sobre o que seja o próprio Direito, que enquanto realidade interpretativa, e não inteiramente objetiva, padece de várias concepções derivadas de opções de moralidade política. Assim, em oposição ao convencionalismo e ao pragmatismo, versões interpretativas do positivismo e do realismo jurídico ${ }^{7}$, o autor apresenta o conceito de integridade no Direito. Nas suas palavras:

\footnotetext{
${ }^{6}$ Nesse estudo, não se pretende entrar no mérito da discussão sobre positivismo inclusivo e positivismo exclusivo, entendendo-se o positivismo jurídico apenas de forma abrangente como uma teoria descritiva do direito.

${ }^{7}$ Para um melhor entendimento acerca da interpretação no convencionalismo e no pragmatismo: "O direito como integridade é, portanto, mais inflexivelmente interpretativo do que o convencionalismo ou o pragmatismo. Essas últimas teorias se oferecem como interpretações. São concepções de direito que pretendem mostrar nossas práticas jurídicas sob sua melhor luz, e recomendam, em suas conclusões pós-interpretativas, estilos ou
} 


\begin{abstract}
A integridade também contribui para a eficiência do direito no sentido que já assinalamos aqui. Se as pessoas aceitam que são governadas não apenas por regras explícitas, estabelecidas por decisões políticas tomadas no passado, mas por quaisquer outras regras que decorrem dos princípios que essas decisões pressupõem, então o conjunto de normas públicas reconhecidas pode expandir-se e contrair-se organicamente, à medida que as pessoas se tornem mais sofisticadas em perceber e explorar aquilo que esses princípios exigem sob novas circunstâncias, sem a necessidade de um detalhamento da legislação ou da jurisprudência de cada um dos possíveis pontos de conflito (DWORKIN, 2014, p. 229).
\end{abstract}

Desse modo, "parte-se da afirmação de que o que caracteriza o Direito é a coerência de princípio, ou seja, uma integridade principiológica compartilhada por uma comunidade e buscada pelo intérprete do ordenamento jurídico" (CAMPOS; ARDISSON, 2013, p. 257-258).

De acordo com a teoria do Direito como integridade, a sociedade é formada por uma comunidade de princípios, sendo tarefa do julgador, no momento de interpretar a legislação para decidir um caso concreto, encontrar na moral política da coletividade a resposta correta.

A teoria da integridade de Dworkin busca que todas as decisões, tanto do julgador quanto do legislador, sejam convergentes ao ponto de vista moral com o restante dos princípios compartilhados:

\begin{abstract}
A teoria interpretativa de Dworkin pode ser inserida na perspectiva mais abrangente do "direito como integridade", na qual todo o Direito e seu conjunto de artefatos, normas, decisões, encontram-se em um processo contínuo de interpretação. A integridade orienta, também, a produção do legislador, de modo que este deve buscar fazer com que o conjunto normativo do Estado se torne moralmente coerente (CLEVE; LORENZETTO, 2016, p. 79).
\end{abstract}

programas diferentes de deliberação judicial. Mas os programas que recomendam não são, em si, programas de interpretação; não pedem aos juízes encarregados da decisão de casos difíceis que façam novos exames, essencialmente interpretativos, da doutrina jurídica. O convencionalismo exige que os juízes estudem os repertórios jurídicos e os registros parlamentares para descobrir que decisões foram tomadas pelas instituições às quais convencionalmente se atribui poder legislativo. É evidente que vão surgir problemas interpretativos ao longo desse processo: por exemplo, pode ser necessário interpretar um texto para decidir que lei nossas convenções jurídicas constroem a partir dele. Uma vez, porém, que um juiz tenha aceito o convencionalismo como guia, não terá novas ocasiões de interpretar o registro legislativo como um todo, ao tomar decisões sobre casos específicos. O pragmatismo exige que os juízes de modo instrumental sobre as melhores regras para o futuro. Esse exercício pode pedir a interpretação de alguma coisa que extrapola a matéria jurídica: um pragmático utilitarista talvez precise preocupar-se com a melhor maneira de entender a ideia de bem-estar comunitário, por exemplo. Uma vez mais, porém, um juiz que aceite o pragmatismo não mais poderá interpretar a prática jurídica em sua totalidade" (DWORKIN, 2014, p. 272-273).

Revista de Teorias do Direito e Realismo Jurídico | e-ISSN: 2525-9601 | Porto Alegre | v. 4 | n. 2 | p. $72-89$ | Jul/Dez. 2018 
A solução para casos difíceis deve ser perseguida, dessa maneira, partindo da ideia de uma comunidade de princípios que representariam a integridade da própria sociedade, caso esta pudesse ser personificada.

Do ponto de vista da garantia fundamental à presunção de inocência associado à teoria da integridade no Direito, deve-se levar em conta que se trata de princípio contido na Constituição Federal que representa a lei fundamental de qualquer Estado de Direito e que espelha uma tradição principiológica iluminista na qual está inserida a comunidade brasileira, refletida em várias decisões políticas ao longo de sua história institucional.

A constituição, neste caso, pode ser vista também como um tipo especial de legislação, de modo que, levado em consideração seu caráter inerente de decisão fundamental principiológica e política da comunidade, ela inevitavelmente deve ser incluída no campo de interpretação construtiva do direito como integridade (CAMPOS; ARDISSON, 2013, p. 262).

Como ponto de partida da sociedade, dessa forma, os princípios constitucionais devem ser considerados de maneira particular, pois, como visto, são o resultado da primeira decisão política e de princípios da comunidade.

Para que haja uma decisão que respeite a integridade, o julgador deveria, portanto, atentar para a comunidade de princípios a fim de identificar qual seria a melhor decisão, considerando não só decisões anteriores como também a moral política da sociedade.

A teoria interpretativista de Ronald Dworkin rejeita a discricionariedade forte do julgador, sendo contrária a qualquer tipo de ativismo ou decisionismo por parte dos órgãos judiciais.

Julgadores deveriam espelhar-se no Juiz Hércules ${ }^{8}$ como modelo ideal a ser buscado na tentativa de encontrar uma resposta correta com base nos princípios partilhados pela sociedade ao invés de decidirem da maneira que desejam, buscando, a posteriori, argumentos (morais, estatísticos, retóricos, etc) para fundamentar sua decisão.

\footnotetext{
${ }^{8}$ Dworkin cria o juiz Hércules como um parâmetro ideal a ser perseguido pelos julgadores. Nas suas palavras: "Podemos, portanto, examinar de que modo um juiz-filósofo poderia desenvolver, nos casos apropriados, teorias sobre aquilo que a intenção legislativa e os princípios jurídicos requerem. Descobriremos que ele formula essas teorias da mesma maneira que um árbitro filosófico construiria as características de um jogo. Para esse fim, eu inventei um jurista de capacidade, sabedoria, paciência e sagacidade sobre-humanas, a quem chamarei de Hércules. Eu suponho que Hércules seja juiz de alguma jurisdição norte-americana representativa. Considero que ele aceita as principais regras não controversas que constituem e regem o direito em sua jurisdição. Em outras palavras, ele aceita que as leis têm o poder geral de criar e extinguir direitos jurídicos, e que os juízes têm o dever geral de seguir as decisões anteriores de seu tribunal ou dos tribunais superiores cujo fundamento racional (rationale), como dizem os juristas, aplica-se ao caso em juízo" (DWORKIN, 2010, p. 165).
} 
Com base nessas considerações, buscar-se-á demonstrar como alguns dos ministros do Supremo Tribunal Federal os quais saíram com seus votos vencedores no julgamento do HC 152.752, utilizando o seu poder discricionário em um sentido forte, decidiram ao fazer uso dos mais variados argumentos sem uma efetiva busca pela resposta correta e pela integridade, incorrendo em grave erro ao permitir a execução provisória da sentença penal condenatória.

\section{O JULGAMENTO DO STF NO HC 152.752 DO PONTO DE VISTA DA COMUNIDADE DE PRINCÍPIOS EM RELAÇÃO A PRESUNÇÃO DE INOCÊNCIA}

A discussão travada pelos ministros do Supremo Tribunal Federal no Habeas Corpus 152.752 girou em torno da possibilidade, ou não, da execução da pena após o julgamento de segunda instância, mas antes do trânsito em julgado da sentença. Não se tratava de um caso de first impression, pois já havia longa jurisprudência sobre o assunto e recente oscilação nela há poucos anos.

Após uma sessão que durou mais de 10 horas, por 6 votos a 5, o tribunal decidiu denegar a ordem, entendendo ser possível o início do cumprimento da pena, independentemente de motivos para uma medida cautelar, após a condenação em segunda instância ainda que exista a possibilidade de recurso para as instâncias superiores. Os votos dos Ministros Roberto Barroso e Rosa Weber merecem atenção.

Em seu voto, o ministro Luís Roberto Barroso fez uma análise história acerca da matéria, destacando que o entendimento do Supremo Tribunal Federal só foi contrário à execução após a condenação em segunda instância do ano de 2009 ao ano de 2016. Em seguida, destacou que, em sua visão, o entendimento firmado nesse período produziu inúmeros efeitos negativos, entre eles "o descrédito do sistema de justiça penal junto à sociedade, pela demora na punição e pelas frequentes prescrições, gerando enorme sensação de impunidade".

Para fundamentar a sua tese de "mutação constitucional", fundamentou sua decisão com base em elementos empíricos, procedendo a análise de vários casos concretos (“caso do jornalista", “caso do senador", "caso do jogador de futebol”, entre outros) e 
revelando dados obtidos por levantamentos nos bancos de dados do Tribunal. Afirmou, ainda, que a execução da pena após a condenação em segundo grau seria uma exigência de ordem pública de modo a preservar a credibilidade da justiça.

Já a Ministra Rosa Weber declarou-se pessoalmente contrária à execução da pena antes do trânsito em julgado em virtude do disposto na Constituição Federal, entretanto surpreendeu ao denegar o Habeas Corpus. Apesar de reconhecer no artigo $5^{\circ}$, LVII da Constituição Federal - o princípio da presunção de inocência, a Ministra optou por invocar um até então desconhecido "princípio da colegialidade", afirmando que se tratava de preceito necessário e suficiente para o sistema, segundo o qual o julgador deve se submeter ao entendimento do colegiado que integra, independentemente de sua própria convicção.

Frise-se, no entanto, que o voto da Ministra Rosa Weber foi decisivo para a manutenção do entendimento pela possibilidade da execução da pena após condenação em segunda instância, isto é, caso a ministra votasse de acordo com sua posição, estaria formada uma nova maioria e, por conseguinte, seria uma decisão do órgão colegiado a ser protegida pelo dito "princípio da colegialidade".

Paradoxalmente, ao fundamentar sua decisão, a ministra cita Dworkin e a teoria da integridade apresentada e discutida no tópico anterior do presente estudo:

\footnotetext{
Esse posicionamento orienta-se, a meu juízo, em compasso com a exortação de Ronald Dworkin, para quem o julgador, diante do caso concreto, não pode jamais abrir mão de buscar a resposta que preserve aquilo que ele chama de integridade do direito (the right answer thesis) (WEBER, 2018, p. 17).
}

Como será visto mais à frente, a ministra, apesar de citar a teoria da integridade de Dworkin, deixou de aplicar no momento de decidir o caso, tendo em vista que não buscou a única resposta correta com base na comunidade de princípios; não se orientou na busca de uma convergência nesse nível substancial, se ocupando, em verdade, com formalidades, pois o que ela chamou de princípio da colegialidade não poderia ser enquadrado como tal na teoria de Dworkin, para quem princípios são normas cuja validade não se deve a um critério formal estabelecido por uma regra de reconhecimento, mas a seu peso e relevância moral. A colegialidade, ao menos da maneira apresentada pela ministra, não possui essa dimensão substancial.

Pela análise, ainda que não tão profunda, do voto dos ministros citados no julgamento do referido Habeas Corpus, percebe-se que a fundamentação utilizada em ambos 
os casos denota, em verdade, um alto grau do exercício de um poder discricionário no sentido forte.

No Brasil, a discricionariedade toma contornos que beiram a arbitrariedade, de modo que juristas utilizam argumentos embasados em princípios (aqui entendidos como valores), inclusive para afastar o texto constitucional, e apostando no protagonismo judicial (STRECK, 2011).

Acerca da abertura proporcionada aos juízes que acaba gerando o fenômeno denominado como decisionismo, possibilitando que o juiz decida o caso como quiser, George Marmelstein afirma o seguinte:

\begin{abstract}
Se, atualmente, admite-se que o juiz pode buscar na própria Constituição a solução para os problemas que tem que resolver (ou até mesmo fora da Constituição!), é natural reconhecer que a "moldura normativa" ganhou dimensões bastante amplas. Dificilmente, será possível estabelecer antecipadamente quais são os limites da resposta judicial no caso concreto, já que a solução dependerá, em grande medida, do poder criativo do juiz (e da mediação do caso concreto), algo que sempre houve, mas nunca com tanta intensidade. Assim, em muitas questões, a atividade dos juízes se assemelhará à atividade de um “intérprete de nuvens", que não vê limites à sua criatividade. Isso dá margem ao florescimento do chamado "decisionismo judicial", que nada mais é do que a atitude do magistrado que julga com base em suas próprias convicções pessoais sem se preocupar em buscar uma objetividade decisória. No fundo, o juiz, pelo menos potencialmente, pode decidir como quiser, ainda que tenha que fundamentar a sua escolha no sistema normativo-constitucional, que, afinal de contas, aceita quase tudo (MARMELSTEIN, 2010, p. 20).
\end{abstract}

No caso em análise, os ministros decidiram contra o direito fundamental à presunção de inocência com base em argumentos empíricos, retóricos e morais eminentemente individuais. Quando muito, o Ministro Barroso trouxe levantamentos sobre a estatística da reversibilidade de decisões de segundo grau na instância extraordinária no Supremo Tribunal Federal, como se a pouca probabilidade de alguém ter um recurso extraordinário provido fosse elemento suficiente para elidir a injustiça sofrida por aquele que, se encaixando no percentual menos provável, venha a ser libertado após período de prisão indevida. Com seu raciocínio, o Ministro Barroso toma uma injustiça dessa natureza como uma situação recalcitrante de pouca importância se for para salvaguardar a certeza de punibilidade: um preso injustamente se justificaria caso se garanta a punição de muitos culpados.

No entanto, o princípio da liberdade, garantido pela presunção de inocência, não comporta tal sorte de restrição geral e abstrata; ao contrário a proíbe, sobretudo porque 
eventual impunidade de culpados se deve mais frequentemente a várias deficiências da estrutura do Judiciário de um modo geral, que poderiam ser enfrentadas e solucionadas sem a restrição de garantias fundamentais. Não é o exercício de direitos fundamentais que necessariamente leva a impunidades.

Outro ponto que pode ser enfrentado pela teoria dworkiniana é a alteração jurisprudencial, que bem expõe a diferença entre coerência e integridade. Enquanto a coerência é a convergência mais imediata ao que fora firmado em decisões anteriores, a integridade importa o dever mais profundo de observância aos princípios que subjazem nos precedentes, ainda que não importe reprodução exata do que se vinha decidindo.

Ao tratar sobre a distinção entre coerência e integridade, Dworkin lança o questionamento: "Será a integridade apenas coerência (decidir casos semelhantes da mesma maneira), sob um nome mais grandioso?" Sua resposta é que ambas são distintas, pois "se uma instituição política só é coerente quando repete suas próprias decisões o mais fiel ou precisamente possível, então a integridade não é coerência; é, ao mesmo tempo, mais e menos" (DWORKIN, 2010, p. 263). A partir daí acrescenta:

A integridade exige que as normas públicas da comunidade sejam criadas e vistas, na medida do possível, de modo a expressar um sistema único e coerente de justiça e equidade na correta proporção. Uma instituição que aceite esse ideal às vezes irá, por essa razão, afastar-se da estreita linha das decisões anteriores, em busca de uma fidelidade aos princípios concebidos como mais fundamentais a esse sistema como um todo.

Diante disso, é possível identificar o seguinte no concernente à jurisprudência em torno do assunto: em 2009, quando houve a mudança de entendimento para proibir a prisão antes do trânsito em julgado, o Supremo Tribunal Federal não foi coerente (já que não repetiu o entendimento firmado anteriormente), mas foi íntegro, porquanto mudou com base em princípios que definem a comunidade brasileira em torno de valores humanos, como a liberdade e a presunção de inocência; em 2016, quando retornou ao velho entendimento jurisprudencial, não foi nem coerente nem íntegro; e pelo julgamento do Habeas Corpus 152.752 foi coerente, mas não foi íntegro.

No entanto, mesmo a coerência pode ser questionada, já que o voto determinante para o resultado foi da lavra da Ministra Rosa Weber, que alterou seu próprio entendimento em função do alegado "princípio da colegialidade" e, ainda pior, anunciou que poderia retornar ao voto anterior diante de um dado absolutamente 
irrelevante, o qual seria o julgamento se dar não em um processo subjetivo como o Habeas Corpus, mas em ações declaratórias de constitucionalidade (processos objetivos) que aguardam pauta de julgamento. Além disso, essas ações declaratórias só não foram julgadas em conjunto com o referido habeas corpus em razão de uma vontade discricionária da Presidente da Corte, Ministra Carmen Lúcia, que decidiu não o fazer e sem apresentar qualquer justificativa para tanto, provocando críticas do Ministro Marco Aurélio Melo. Enfim, imperou uma discricionariedade forte no julgamento, mesmo em sua fase preliminar e não judicial de definição da própria pauta de julgamento.

Dúvidas não há a respeito da moral política da sociedade acerca do princípio da presunção de inocência como direito fundamental, tendo em vista existir um consenso, construído ao longo de muito tempo, de que a liberdade é um bem muito caro e deve ser protegido até que se esgotem todas as possibilidades.

Tanto a Constituição Federal quanto o Código de Processo Penal também corroboram para comprovar que a presunção de inocência está inserida no âmbito do que a sociedade entende como justo, equitativo e moral.

Caso os ministros tomassem o Direito como integridade no julgamento do Habeas Corpus 152.752, certamente argumentos como "preservar a credibilidade da justiça" e "aplicar o princípio da colegialidade" desapareceriam, pois os julgadores chegariam a comunidade de princípios, verificando que a presunção de inocência faz parte da moral política da sociedade.

\section{CONCLUSÃO}

O princípio da presunção de inocência, positivado como garantia individual no artigo 5 , LVII da Constituição Federal de 1988, representa uma garantia fundamental. O desrespeito a essa prescrição ofende o direito de liberdade e, consequentemente, fere frontalmente o princípio da dignidade da pessoa humana que é o fundamento máximo do ordenamento jurídico brasileiro.

Além de estar positivado na Constituição e no Código de Processo Penal, a presunção de inocência é, antes de tudo, um princípio da sociedade que vem sendo construído ao longo do tempo. O senso de justiça e equidade da comunidade prevê que um indivíduo 
apenas pode começar a cumprir uma pena de prisão após o esgotamento de todas as possibilidades recursais.

As teorias positivistas do Direito, preocupadas em analisar o fenômeno jurídico de forma apenas descritiva, acabaram pecando no desenvolvimento de uma teoria interpretativa, deixando para o julgador uma margem considerável para decidir casos concretos, ou seja, os intérpretes teriam um poder discricionário acentuado, podendo escolher uma dentre várias decisões possíveis.

Ronald Dworkin buscou tratar o Direito a partir de uma teoria interpretativa, construindo, ao longo de sua vida, uma doutrina interpretativista que culminou na integridade no Direito e com a tese da única resposta correta. A tentativa era demonstrar que os julgadores não possuem poder de escolher uma entre várias decisões, mas que devem chegar sempre a uma decisão que seria aceitável a partir de uma comunidade de princípios.

No julgamento do Habeas Corpus 152.752, o Supremo Tribunal Federal decidiu por permitir o início da execução da pena de prisão após o julgamento em segunda instância ainda que exista a possibilidade de recurso para as instâncias superiores.

Ao analisar os argumentos utilizados pelos ministros nos votos vencedores, especificamente do Ministro Luís Roberto Barroso e da Ministra Rosa Weber, percebe-se que a fundamentação das decisões está diretamente ligada ao poder discricionário que beira a arbitrariedade.

Entre fundamentos como preservar a credibilidade da justiça e prestigiar o princípio da colegialidade, percebe-se que os ministros exerceram um decisionismo em um indevido protagonismo judicial para criar o Direito conforme convicções individuais e não íntegras.

Essa tem sido uma característica no Direito brasileiro: cada vez mais, juízes decidem casos concretos como determinam suas consciências individuais, aproveitando-se do poder discricionário para, muitas vezes, afastarem a aplicação da lei ou mesmo da própria Constituição Federal.

Resultado diferente teria o julgamento se a teoria da integridade proposta por Dworkin fosse aplicada para a decisão do citado Habeas Corpus. Em busca da única resposta correta, investigando a comunidade de princípios, os ministros certamente chegariam na interpretação de que a moralidade política da sociedade entende ser o princípio da presunção 
de inocência um direito fundamental, especialmente na proteção de um dos bens mais valiosos do ser humano que é a liberdade.

Não é admissível, de acordo com o senso de justiça e equidade presente na sociedade, que um cidadão seja privado de sua liberdade antes mesmo de se esgotarem as possbilidades recursais. Se existe uma pequena chance de que seja cometida uma injustiça, não se pode admitir que um ser humano inicie o cumprimento de uma pena de prisão caso ainda lhe restem recursos jurídicos a serem manejados.

\section{REFERÊNCIAS}

BRASIL. Constituição (1988). Constituição da República Federativa do Brasil: promulgada em 5 de outubro de 1988, atualizada até a Emenda Constitucional n ${ }^{\circ}$ 91, de 18 de fevereiro de 2016. Disponível em: 〈https://goo.gl/TyW2aY >. Acesso em: 20 jun. 2018.

BRASIL. Decreto-lei n. 3.869. Código de Processo Penal, de 03 de outubro de 1941. Disponível em: < https://goo.gl/nVXmW4>. Acesso em: 21 jun. 2018.

BRASIL. Supremo Tribunal Federal. Habeas Corpus n. 152752. Disponível em: < https://goo.gl/ofHijc >. Acesso em: 10 jun. 2018.

CAMPOS, Adriana; ARDISSON, Daniel Piovanelli. O direito como integridade na jurisdição constitucional: análise sobre o aborto segundo a proposta de Ronald Dworkin. Sequência (Florianópolis), Florianópolis, n. 67, p. 251-276, dez. 2013. Disponível em: < https://goo.gl/WvZ4Dw >. Acesso em: 20 jun. 2018.

CLEVE, Clèmerson Merlin; LORENZETTO, Bruno Meneses. Interpretação Constitucional: entre dinâmica e integridade. Sequência (Florianópolis), Florianópolis, n. 72, p. 67-92, abr. 2016. Disponível em: < https://goo.gl/DWAQKe >. Acesso em: 23 jun. 2018.

CÓDIGO PROCESSO PENAL. Brasília: Senado Federal, Coordenação de Edições Técnicas, 2017. 187 p.

DWORKIN, Ronald. Levando os Direitos a Sério. 3. ed. São Paulo: Martins Fontes, 2010. $568 \mathrm{p}$.

O Império do Direito. 3. ed. São Paulo: Martins Fontes, 2014. 513 p.

FERRAJOLI, Luigi. Teoria dos Direitos Fundamentais. In: LIMA NETO, Francisco Vieira (Org.). Temas Atuais de Direito. Rio de Janeiro: Lumnes Juris, 2011. p. 501-526.

GOMES, Luiz Flávio. Sobre o conteúdo processual tridimensional do princípio da presunção de inocência. Revista dos Tribunais, São Paulo, v. 85, n. 729, p. 377-387, jul. 1996.

Revista de Teorias do Direito e Realismo Jurídico | e-ISSN: 2525-9601 | Porto Alegre | v. 4 | n. 2 | p. $72-89$ | Jul/Dez. 2018 
HART, H.L.A. O Conceito de Direito. São Paulo: Martins Fontes, 2009.

KELSEN, Hans. Teoria Pura do Direito. São Paulo: Martins Fontes, 1999.

MACHADO SEGUNDO, Hugo de Brito Machado. Por que Dogmática Jurídica? Rio de Janeiro: Forense, 2008.

MARMELSTEIN, George. A Difícil Arte de Ponderar o Imponderável: reflexões em torno da colisão de direitos fundamentais e da ponderação de valores. In: LEITE, George; SARLET, Ingo; CARBONNEL, Miguel. Direitos, Deveres e Garantias Fundamentais. Salvador: JusPodivm, 2010.

$536 \mathrm{p}$.

Curso de Direitos Fundamentais. 5. ed. São Paulo: Atlas, 2014.

NICOLITT, André Luiz. Habeas Corpus 118.770 do STF: direitos fundamentais contra direitos fundamentais: mais uma violência à presunção de inocência. Revista dos Tribunais, São Paulo, v. 106, n. 983, p. 155-174, set. 2017.

OLIVEIRA NETO, Emetério Silva de. Garantismo penal e presunção de inocência: uma análise do habeas corpus 126.292. Revista Brasileira de Ciências Criminais, São Paulo, v. 26, n. 142, p. 133-170, abr. 2018.

PEREIRA, Jane Reis Gonçalves. Interpretação Constitucional e Direitos

Fundamentais: Uma contribuição ao estudo das restrições aos direitos fundamentais na perspectiva da teoria dos princípios. Rio de Janeiro: Renovar, 2006. 563 p.

ROBLES, Gregório. Los Derechos fundamentales y la ética en la sociedade actual. Madrid: Editora Civitas, 1992. p. 11-32.

SHAPIRO, Scott J.. The Hart-Dworkin Debate: A Short Guide for the Perplexed. SSRN Electronic Journal, New York, p.1-54, mar. 2007. Disponível em: < https://goo.g1/hRxa6G $>$.

SILVA, José Afonso da. Curso de Direito Constitucional Positivo. 37. ed. São Paulo: Malheiros Editores, 2014. 934 p.

STRECK, Lenio Luiz. Verdade e Consenso: Constituição Hermenêutica e teorias discursivas. São Paulo: Saraiva, 2011. 